\title{
Environmental factors influencing leisure participation of children with movement impairments in Aotearoa/New Zealand: A mixed method study
}

Parimala S. Kanagasabai BPT, MPT, PhD

Research assistant, School of Physiotherapy, Centre for Health, Activity and Rehabilitation, University of Otago, Wellington, New Zealand

Hilda Mulligan BSC (Physio), MHealsc, PhD

Senior lecturer, School of Physiotherapy, Centre for Health, Activity and Rehabilitation, University of Otago, Dunedin, New Zealand

Hemakumar Devan BPT, MPhty, PhD

Postdoctoral fellow, School of Physiotherapy, Centre for Health, Activity and Rehabilitation Research, University of Otago, Wellington, New Zealand

Brigit Mirfin-Veitch $B A, B A$ (Hons), PhD

Director, Donald Beasley Institute, Dunedin, New Zealand

Leigh A. Hale BSc (Physio), MSc, PhD

Professor and Dean, School of Physiotherapy, Centre for Health, Activity and Rehabilitation Research, University of Otago, Dunedin, New Zealand

\section{ABSTRACT}

We conducted a mixed method study to explore the environmental factors affecting leisure participation of children with movement impairments aged six to 12 years in Aotearoa/New Zealand. Families of children with movement impairments completed the "Craig's Hospital Inventory of Environmental Factors for Children-Parent Version" questionnaire and in-depth individual interviews of children, along with their parents or guardian, were undertaken. Fifty-nine families participated in the survey, with 22 of these also participating in the interview. We used descriptive statistics for quantitative data and the general inductive approach to analyse the qualitative data. The findings of each were then integrated. We found a mismatch between a child's ability and existing leisure activity opportunities/choices at various settings. Restrictions to participation included non-inclusive school-based physical education programmes, limited tailoring of community-based programmes and inaccessible neighbourhood environments. To maximise the leisure activity opportunities in Aotearoa/New Zealand, concerted efforts are required by health professionals, including physiotherapists, schools, disability organisations and policymakers, to create and offer adaptive and/or inclusive leisure activity programmes to children of all ages and abilities at their school, community and local neighbourhood.

Kanagasabai, P. S., Mulligan, H., Devan, H., Mirfin-Veitch, B., \& Hale, L. A. (2019). Environmental factors influencing leisure participation of children with movement impairments in Aotearoa/New Zealand: A mixed method study. New Zealand Journal of Physiotherapy, 47(2), 105-117. https://doi.org/10.15619/NZJP/47.2.05

Key Words: Children, Environmental Barriers, Leisure Participation, Movement Impairments

\section{INTRODUCTION}

According to the World Health Organisation's framework of functioning, disability and health for children (World Health Organisation, 2007), restrictions to children's participation can occur during the interaction of a child with his or her surrounding environment. This could include all or any aspects of the physical environment and the child's functional ability within that environment, the family and community environment, the societal environment and services, and systems and policies that impact on them. In particular, leisure participation levels of children with impairments are reportedly influenced by environmental factors relating to a country or region-specific context, such as government policies, accessibility of public places, availability of after-school recreation centres and provision of support services (for example, information about available assistive technology) (Anaby et al., 2013; Hammal, Jarvis, \& Colver, 2004; King et al., 2013; Michelsen et al., 2009; Shikako-Thomas, Majnemer, Law, \& Lach, 2008; Ullenhag et al., 2012; Welsh, Jarvis, Hammal, \& Colver, 2006). Specifically, King et al. (2013) have suggested that country of residence is the most important predictor influencing involvement in recreational and social activities of children with movement impairments.

Given the importance that country or region-specific environmental issues have in leisure participation, investigating the environmental factors that influence leisure participation in children with movement impairments is essential for developing specific intervention plans and modifications relevant to issues in a particular region. As well as investigating the contextual influences, it is also important to consider individual family 
requirements within their environment and to identify the support required by a particular child and family. For example, a family with high socio-economic status may not report transportation as a barrier as they are likely to have their own mode of transportation (Bedell et al., 2013; Kramer, Olsen, Mermelstein, Balcells, \& Liljenquist, 2012; Shimmell, Gorter, Jackson, Wright, \& Galuppi, 2013).

Therapists could play an important role in improving children's participation in the community, including leisure participation, by identifying barriers in a child's individual context and identifying or providing solutions to address such barriers (Almqvist, Uys, \& Sandberg, 2007; Majnemer, 2009). To date, no research has examined environmental factors that influence involvement in leisure activities by children with movement impairments in the Aotearoa/New Zealand context. Hence, the aim of this paper was to identify and explore common environmental factors that influence leisure participation by children with movement impairments in Aotearoa/New Zealand, and to recommend possible ways to improve their involvement in leisure activities.

\section{METHODS}

We used a convergent parallel design (Creswell \& Plano Clark, 2011), where both a survey and an interview were conducted to complement each other and yield a deeper understanding of the leisure participation of children with movement impairments. The survey was used to identify common environmental factors that influence leisure participation, and the semi-structured qualitative interview framework was used to describe in-depth how environmental barriers can work to restrict the leisure participation. Ethical approval for both the survey and the interview were obtained from the University of Otago Human (Health) Ethics committee (ref: 12/314 and 13/132).

We recruited, nationwide, children aged six to 12 years with movement impairments who had the ability to understand simple questions. Specifically, we recruited children through 11 national and local disability organisations; the Child Development Centres of two large District Health Boards (Auckland and Canterbury); 35 therapists working for the Ministry of Education in schools; and the Movement Development Clinic in the School of Physical Education of a tertiary education institution. The study information was sent to families by direct contact (for example, the researcher, therapist or personnel at the agency contacted families in person or by telephone) or by indirect contact, such as posting flyers, emails, and advertising in websites and magazines.

We conducted a large survey to investigate leisure participation patterns and factors influencing leisure participation of children with movement impairments in Aotearoa/New Zealand (Kanagasabai, Mulligan, Hale \& Mirfin-Veitch, 2017). To investigate the environmental factors, we used the Craig's Hospital Inventory of Environmental Factors (CHIEF) for ChildrenParent Version. This questionnaire is easy to complete, has good test-retest reliability (intraclass correlation coefficient, 0.73 ) and has an acceptable measure of parental perceived environmental barriers for children with impairments aged two to 12 years (McCauley et al., 2012). It is a 10-item questionnaire that measures barriers to participation within the physical (two items), attitudinal (two items), service (three items), productivity (one item) and policy (two items) environments in the school and community contexts. It measures two dimensions: frequency (how often a particular barrier is a problem for the child); and magnitude (whether the barrier is a big or small problem). Frequency questions are scored from 0 (never a problem) to 4 (daily problem); magnitude questions are scored as either 1 (little problem) or 2 (big problem). The questionnaires were mailed to families who expressed interest in the study, and the completed questionnaires were returned via a self-addressed envelope.

Children who participated in the survey were purposively sampled for the interview to include various environmental settings across Aotearoa/New Zealand (the greater Auckland area, Wellington, Canterbury, Dunedin and Invercargill) and different levels of impairments. We used a child-centred method of data collection that included strategies such as semi-structured interviews; drawing; sharing photographs: playing quiet games; and demonstrating activities, equipment and leisure environments. The data collection strategies are described in detail in a previous paper (Kanagasabai, MirfinVeitch, Hale \& Mulligan, 2018).

\section{Data analysis}

Data from the CHIEF for Children-Parent Version questionnaire were analysed using descriptive statistics for demographic data, and by calculating the frequency and magnitude of perceived environmental barriers.

The general inductive approach (Thomas, 2006) was used for analysis of the qualitative data. This approach is essentially evaluative and uses a constant comparative framework guided by the research objectives. Based on this approach to analysis, the raw texts were read multiple times to form initial categories relevant to the main aims of the study (Thomas, 2006). Subsequently, the initial categories were merged to identify the final categories, and then to build a model illustrating the relationships between the final categories. Two researchers (PS and $\mathrm{HD}$ ) independently coded the qualitative data and identified the final categories to create the model. Then, three authors (HM, LH and BMV) commented on the final categories and the model. After numerous discussions, the model and its categories were derived by consensus.

Integration of qualitative and quantitative data is one of the key methodological concerns in mixed method studies (Creswell \& Plano Clark, 2011). For this study, the findings from both the interviews and survey were integrated by simultaneously comparing and relating the data to each other (Creswell \& Plano Clark, 2011). To collate the findings, the qualitative data exploring the impact of environmental barriers on leisure participation were complemented by the quantitative data of the frequency of common environmental barriers to leisure participation.

\section{RESULTS}

Of the 79 families who expressed an interest in participating in the study, 59 completed the survey. Of these, 22 families participated in an interview. Demographic details of the survey 
and interview participants are presented in Table 1. The children who participated in the study had a variety of diagnoses, including cerebral palsy, muscular dystrophy, dyspraxia, spina bifida and arthrogryposis as well as other conditions resulting in impaired movement (for example, congenital syndromes, amputation). The majority of children had problems with mobility, along with problems with dexterity and agility. Most families lived in densely populated city and town regions, rather than in sparsely populated rural areas.

The integrated findings of the survey and interviews are presented below. Table 2 shows the frequency and magnitude of environmental barriers to participation of children with movement impairments, as perceived by their parents or guardian. Table 3 shows the main categories from the qualitative inductive analysis. A conceptual diagram of findings derived from both phases is presented in Figure 1.

Children in our study perceived that nothing stopped them from having fun, and they carefully selected their leisure activities and leisure environment and/or followed various adaptations to participate in an activity. However, children and their families reported various barriers in their environment that limited their opportunities for leisure activities. The overarching integrated theme was "Mismatch between individual abilities and leisure activities choices".

I personally don't feel there is a whole lot out there for our kids so I work at trying to make things happen. A lot of what is out there is not well publicised. With a huge population of Auckland, I am often surprised how little other kids get involved. I am sure there are a number of different reasons. I have always assumed [child's name] can participate in what interests him, and work out a way to make it possible. Still wish there would be more wheelchair sports events. (Parent \#9)

This theme manifested in various environments, such as in the community, at school and within neighbourhoods, and is presented in more detail under subheadings below.

Table 1: Demographic details of survey and interview participants

\begin{tabular}{|c|c|c|c|}
\hline \multicolumn{2}{|l|}{ Survey participants $(n=59)$} & \multicolumn{2}{|l|}{ Interview participants $(\mathrm{n}=22)$} \\
\hline Age (years), mean (SD) & $8.9(1.6)$ & Age (years), mean (SD) & $8.7(2.0)$ \\
\hline Sex, n male (\%) & $40(67.8)$ & Sex, n male (\%) & $15(68.2)$ \\
\hline $\begin{array}{l}\text { Diagnosis, } \mathrm{n}(\%) \\
\text { Cerebral Palsy } \\
\text { Amputation } \\
\text { Dyspraxia } \\
\text { Muscular dystrophy } \\
\text { Spina bifida } \\
\text { Arthrogryposis } \\
\text { Other }\end{array}$ & $\begin{array}{l}26(44) \\
7(11.8) \\
7(11.8) \\
4(6.7) \\
2(3.4) \\
2(3.4) \\
11(18.6)\end{array}$ & $\begin{array}{l}\text { Diagnosis, } \mathrm{n}(\%) \\
\text { Cerebral Palsy } \\
\text { Amputation } \\
\text { Arthrogryposis } \\
\text { Spina bifida } \\
\text { Ataxia telangiectasia } \\
\text { Hereditary chorea } \\
\text { Hypermobile joints } \\
\text { Hemiparesis }\end{array}$ & $\begin{array}{l}11(50) \\
4(18.2) \\
2(9.1) \\
1(4.5) \\
1(4.5) \\
1(4.5) \\
1(4.5) \\
1(4.5)\end{array}$ \\
\hline $\begin{array}{l}\text { Problems with*, n (\%) } \\
\text { Mobility } \\
\text { Dexterity } \\
\text { Agility }\end{array}$ & $\begin{array}{l}48(81.3) \\
29(49.1) \\
32(54.2)\end{array}$ & $\begin{array}{c}\text { Problems with*, n (\%) } \\
\text { Mobility } \\
\text { Dexterity } \\
\text { Agility }\end{array}$ & $\begin{array}{l}18(81.8) \\
9(40.9) \\
8(36.4)\end{array}$ \\
\hline $\begin{array}{l}\text { Associated problems*, n (\%) } \\
\text { Hearing } \\
\text { Vision } \\
\text { Speech } \\
\text { Cognition } \\
\text { Incontinence } \\
\text { Other (seizures, apnoea) }\end{array}$ & $\begin{array}{l}4(6.7) \\
14(23.7) \\
14(23.7) \\
10(16.9) \\
8(13.5) \\
4(6.7)\end{array}$ & $\begin{array}{l}\text { Associated problems*, n (\%) } \\
\text { Hearing } \\
\text { Vision } \\
\text { Speech } \\
\text { Cognition } \\
\text { Incontinence } \\
\text { Coordination }\end{array}$ & $\begin{array}{l}1(4.5) \\
3(13.6) \\
4(18.2) \\
3(13.6) \\
1(4.5) \\
1(4.5)\end{array}$ \\
\hline $\begin{array}{l}\text { Community type, n (\%) } \\
\text { City } \\
\text { Town } \\
\text { Rural area }\end{array}$ & $\begin{array}{l}29(49.1) \\
25(42.4) \\
5(8.5)\end{array}$ & $\begin{array}{c}\text { Community type, n (\%) } \\
\text { City } \\
\text { Town } \\
\text { Rural area }\end{array}$ & $\begin{array}{l}12(54.5) \\
8(36.4) \\
1(4.5)\end{array}$ \\
\hline
\end{tabular}

Notes: n, number; SD, standard deviation; *More than one option possible 
Table 2: Families' perceived environmental barriers, frequency and magnitude $(n=59)$

\begin{tabular}{|c|c|c|c|c|c|c|c|}
\hline \multirow{2}{*}{$\begin{array}{l}\text { Environment context } \\
\text { (10 items) }\end{array}$} & \multirow{2}{*}{$\begin{array}{c}\text { Number } \\
\text { affected (\%) }\end{array}$} & \multicolumn{4}{|c|}{ Frequency } & \multicolumn{2}{|c|}{ Magnitude } \\
\hline & & Daily & Weekly & Monthly & $<$ Monthly & $\begin{array}{l}\text { Little } \\
\text { problem }\end{array}$ & Big problem \\
\hline $\begin{array}{l}\text { Natural environment: } \\
\text { temperature, terrain }\end{array}$ & $47(79.7)$ & $19(32.2)$ & $10(16.9)$ & $6(10.2)$ & $12(20.3)$ & $26(44.1)$ & $21(35.6)$ \\
\hline $\begin{array}{l}\text { Child's surroundings: } \\
\text { noise, crowd }\end{array}$ & $43(72.9)$ & $5(8.5)$ & $12(20.3)$ & $5(8.5)$ & $21(35.6)$ & 35 (59.3) & $8(13.6)$ \\
\hline Information format & $30(50.8)$ & $9(15.2)$ & $3(5.1)$ & $8(13.6)$ & $10(16.9)$ & $22(37.3)$ & $8(13.6)$ \\
\hline Healthcare services & $34(57.6)$ & $2(3.4)$ & $2(3.4)$ & $11(18.6)$ & $19(32.2)$ & $19(32.2)$ & $15(25.4)$ \\
\hline Assistance at school & $42(71.2)$ & $17(28.8)$ & $7(11.9)$ & $3(5.1)$ & $15(25.4)$ & $27(45.8)$ & $15(25.4)$ \\
\hline Others' attitudes & $45(76.3)$ & $5(8.5)$ & $9(15.2)$ & $10(16.9)$ & $21(35.6)$ & $32(54.2)$ & $13(22.03)$ \\
\hline $\begin{array}{l}\text { Support and } \\
\text { encouragement }\end{array}$ & $35(59.3)$ & $4(6.8)$ & $10(16.9)$ & $7(11.9)$ & $14(23.7)$ & $21(35.6)$ & $14(23.7)$ \\
\hline Discrimination & $40(67.8)$ & $2(3.4)$ & $7(11.8)$ & $11(18.6)$ & $20(33.9)$ & $22(37.3)$ & $18(30.5)$ \\
\hline $\begin{array}{l}\text { Community services and } \\
\text { programmes }\end{array}$ & $36(61.0)$ & $2(3.4)$ & $12(20.3)$ & $5(8.5)$ & $17(28.8)$ & $21(35.6)$ & $15(25.4)$ \\
\hline $\begin{array}{l}\text { Education programmes } \\
\text { and policies }\end{array}$ & $34(57.6)$ & $6(10.2)$ & $9(15.2)$ & $4(6.8)$ & $15(25.4)$ & $14(23.7)$ & $20(33.9)$ \\
\hline
\end{tabular}

Table 3: Main categories from inductive analysis

\begin{tabular}{|c|c|c|c|}
\hline $\begin{array}{l}(1) \\
(2)\end{array}$ & $\begin{array}{l}\text { Main category and } \\
\text { subcategory }\end{array}$ & Participant ID & Supporting quotes \\
\hline \multirow[t]{3}{*}{ (1) } & $\begin{array}{l}\text { Limited community } \\
\text { programmes/teams }\end{array}$ & Parent \#20 & $\begin{array}{l}\text { We do think as he gets older that we probably do want to put him into some sort of } \\
\text { sport but with other kids it really is quite hard because he's so... He sort of doesn't } \\
\text { really fit in either world. Because of the way his legs are, he can't really compete in }\end{array}$ \\
\hline & Teams not available & & $\begin{array}{l}\text { anything in the able bodied world. Yeah, so something like kayaking because you } \\
\text { don't need your legs. Anyway, he can compete fairly but even in T-ball he won't be } \\
\text { able to run. He can't play soccer or any of those things but then the disabled sports } \\
\text { are really disabled so they're like, I've looked into the tennis but it's in wheel, a lot } \\
\text { of its in wheelchairs... So it's like really disabled kids or completely able bodied. Like } \\
\text { we've spent a lot of time going into the disabled world to see if we can find kids like } \\
\text { [child's name] and its very rare that... So there's lots of kids who have like cerebral } \\
\text { palsy and things like that who have the same sort of physical ability but cognitively } \\
\text { they're not right so it's very hard. He sort of doesn't fit anywhere. But we'll find } \\
\text { something one day. But he also doesn't think there's anything wrong with him. Like } \\
\text { he knows there is. It's not that he's in denial but he just does everything... }\end{array}$ \\
\hline & & & $\begin{array}{l}\text { But then I think the thing is it's like they can't really develop teams for kids like } \\
\text { [child's name] because there's not enough of them. Because in a city, like even } \\
\text { though we're in Auckland which is a bigger city, there's still... Like 'cause we've } \\
\text { been to two or three of these events where there's all the kids pool from all over } \\
\text { Auckland. And all the physiotherapists try and get them together but there's still } \\
\text { hardly any. }\end{array}$ \\
\hline
\end{tabular}


(1) Main category and

(2) subcategory

(2) Lack of information and lack of programmes for children with impairments
Participant ID Supporting quotes

Parent \#14

I don't know, because... I mean they (disability organisation), haven't mentioned anything. I mean the, the stuff that [child's name] does is sort of individual. So yeah archery, swimming, cycling... on his own modified bike... um, and that's all stuff that we've instigated... there's nothing we have been told about anything... we are completely unaware of whether there's any team sports in Wellington or not.

You know he's pretty busy, but we've never been told about any, any, any team sports that he could participate in.......yeah. Because through Parafed there's team sports but I think it's sort of more targeted to older groups... We would find something which I will be able to do, which I will take an interest in it.

Child \#14 I used to play Boccia ... people with cerebral palsy version of Boccia and I did enjoy (11 years) it, but we just run out of time, yeah. And also one of the reasons why we stopped going to that was because it was mainly adults, and there weren't many children... was a real shame.

Parent \#9 I personally don't feel there is a whole lot out there for our kids so I work at trying to make things happen. A lot of what is out there is not well publicised. With a huge population of Auckland I am often surprised how little other kids get involved. I am sure there are a number of different reasons. I have always assumed [child's name] can participate in what interests him, and work out a way to make it possible. Still wish there would be more wheelchair sports events.

Parent \#9 So a lot of his activities, you know he's very out there but, in some respects, he's still a little too young to really get into somewhere, like wheelchair rugby for example. I mean he's just a little too small to be able to activate and get involved so as he gets older, when he gets to 10 or 12 years old... but even basketball, he's active in basketball but unfortunately there's no league his age, and so the juniors which are typically 14 and up, he can't throw the ball high enough but he goes and he participates in it um 'cause he's a good defensive player kind of thing so, again, activity levels for his age are just scarce.

Parent \#10 There is not a lot for wheelchair people in general because there are not many wheelchair people so they can't have a team or anything as such, because they wouldn't have enough to form a team. So if there was, I think he would have good go at it if they had wheelchair sports. Or just say if it was sports but I don't think there would be enough children or even adults for that matter to fill the team or warrant that, which is a shame.

Parent \#15 I really like the idea of having him [child] as part of a team, but I can also see that that can be quite hard. I guess coming home from football was often, oh [elder brother's name] how many goals have you scored today? And [child's name] was, I remember the day when he was saying, mum, mum, I almost got the ball today. And that can be a bit of a hard, you know if you always feel that you can't quite keep up. In terms of that actually you know it would be fantastic if we could find a football team with other kids that had similar issues, you know that would be the ideal.

Parent \#5 He like, [child's name] gives anything a go... and to the best of his ability but um, yeah there's not, I think down here we're limited and I mean we'll look into it as he gets older, but there's not a lot of opportunities for um people in wheelchairs to do like sporting activities. Like you know bigger centres would have the wheelchair basketball and things like that. But there's nothing like that for children. There are no opportunities and we just keep having to say wait until you get older. I know they have an adult's wheelchair basketball... 
(1) Main category and

(2) subcategory

(2) Lack of disability sports Parent \#3 in rural areas

(2) Lack of indoor sports

(1) School physical education not inclusive

(2) Competitive nature of school sports

Parent \#4
Participant ID Supporting quotes

Rural living has plusses, e.g. good local school, friends. But would often like to live nearer to city for sports, library, swimming etc and to do things with other kids with similar ability. For example, netball etc. can be challenging when [he] can't use one arm very well.

Parent \#5 But yeah I think being in a smaller town that we are a wee bit limited when it comes to children's activities.

Parent \#17 In winter, nothing. Every day here in the home... she may get cold. Winter not too much to do. We stay at home, and summer [child's name] goes to park and beaches, sometimes swimming and sometimes tramping, so winter not much watching TV, cooking. In summer it is nice. It's very different.

As they grow, it is harder to fit in. Sometimes joining in a team was a bit too complicated because they have to totally alter stuff to fit her in so it's kind of slightly... When she was little, she used to play tee ball with the kids at (previous) school. Like they used to include her. But they don't do it at schools in Gore. Now she is big and the sports teams are way more competitive. So they are hard to totally change what they are doing so that she can join in.

Parent \#21 She basically tries to give everything a go so... She hasn't played sports for school since primary school. Three or four years ago now. You don't play in any sports teams do you [child's name]? 'Cause they're too fast for you now...

[Child's name] is only doing swimming due to the invite by Paralympics. She isn't doing anything else. As far as other sports for her, we haven't found anything where she would feel included. When she was younger, she tried for soccer but the school she was in was not very inclusive and only ever picked players so they would win. She did play hockey in years 5 and 6 as her dad was the coach (although other kids still wouldn't pass the ball to her).

Parent \#5 When he was smaller, he used to participate more in things like cricket and that at school. He wanted to play cricket but as the kids get older, they do get more competitive and I don't want them to be nasty to [child's name] because he's not as able as them. So that's probably one of my big reasons for not letting [child's name] try and do competitive sports.

Child \#2 Um, basically, it's just like stuff about the disability, like PE, it's like all running based (12 years) and, basically, at school I don't like PE. I mean I just like don't enjoy it because like they don't like do the kind of sports that I do, like... they do like running-based sports and you know that's obviously not the best thing for me so yeah.

Parent \#9 It's a struggle for, I think, schools when they only have one or two or three, or a small group of children who can't participate, and you know the teachers aren't educated in this sort of stuff and they don't have experience with, it's a struggle... Um, we like the school because of the culture of the school and kind of teaching methodologies but when it comes to some of the physical type things, they struggle to understand just the subtleties of the child with physical disabilities.
2) Lack of support for adapted sports in physical education 
(1) Main category and

(2) subcategory
Participant ID Supporting quotes

Parent \#17

Normally [child's name] can walk short distances. She normally uses a wheelchair for long distances. But in school [child's name] plays just [a] short time with her friends walking. But playing this is the most difficult activity for her. We told the teachers and explained that [child's name] needs to be involved in physical activities but the teacher does not have time may be not enough time to supervise [child's name] activities. I think.

Parent \#20 For all the kids like [child's name] the school sports things, the big school athletics days... they never can compete really... We go to quite a lot of the disabled sports things that they put on like the events around.

That was one put on at [school's name] wasn't it? And you (child) won the best tennis player. So it's great, they can go and compete, and because he's actually very limited in his disability compared to most of the kids there, you clean them up don't you? You always win heaps.

Parent \#17 Sometimes [child's name] is not happy and sad. My friend today did not play with me. Sometimes she feels different. Very different. Why I can't walk fast? A lot of question we can't response everything (sic). It is too hard for her, too hard for us.

Parent \#8 So when you say friends, can I say [child's name] that you don't have a large number of friends... that's a difficult part at school and I think part of that is because of the differences he shows whilst at school. I think that does actually isolate... children that are a little bit different... yeah to some degree because it's easier for a child to go and play with someone that's, can do everything than someone that maybe doesn't look good at what they do.

(1) Inaccessible neighbourhood

(2) Inaccessible homes of friends

Parent \#4

We got (a friend in neighbourhood). She used to go down (to her friend's place in the neighbourhood) every day and the mum had to set up the couch and stereo and stuff in the garage. They used to go down there in the garage because she can't just go to someone's house, because she can't get inside. So because most houses aren't wheelchair friendly we had to put the wooden piece on the front, so that we can get her. So of course most kids' houses aren't wheelchair friendly she can't just go to someone's house. So it's a more complicated when they can't just go somewhere. Houses aren't wheelchair friendly, so we need to be choosy and it requires lot of preparation.

We are just waiting for [name of the facility] to get a better change table for the pool. Because her change table is only as this big [gesticulating] so you put her on it and her head touches the end and her legs will hang off the other end so it's not the best.

Child \#6 Playing on the monkey bar is a bit hard sometimes. I can't really swing on from one (11 years) side to the other.

Child \#9w
I... sometimes I play with the next-door neighbour. Yeah, 'cause both of us, he's about a year younger... just hang around and... it's pretty safe back here so we just go back and forth between the houses, there's nowhere else really to go. 


\section{PERCEIVED BARRIERS}

Community

- Limited choice of adapted individual and team sports

- Limited frequency of available adapted sports

- Lack of information on available leisure activities

School

- Non-inclusive competitive team sports

- Non-inclusive physical education

Neighbourhood

- Inaccessible parks and playgrounds
Community

- Providing information on available adapted sports

- Organising inclusive community sports

- Maximising opportunities for adapted indoor activities

- Suggest adaptive sports equipments

School

- Ongoing communication and support with PE teachers for identifying suitable activities

Neighbourhood

- Advocating for universal design to access community pools and parks for all ages and abilities

Figure 1: Perceived environmental barriers and the potential role of physiotherapists and occupational therapists in addressing those barriers to maximise leisure opportunities for children with movement impairments in Aotearoa/New Zealand

\section{Community}

Lack of community programmes including adapted sports was reported as a barrier by $61 \%$ of families. From the qualitative data, parents in many regions expressed dissatisfaction with the limited availability and suitability of community-based adapted sports for their children. In addition, while some children were able to participate in adapted sports, which they enjoyed, these were available only in a few places and mainly on an infrequent basis. For example, Sanitarium's Weet-Bix Kids TRYathlon (an inclusive, modified sport consisting of swimming, running and biking) is conducted in 18 different regions of Aotearoa/ New Zealand, but available only once a year in a particular region. Furthermore, adapted sports programmes for children conducted by some regional disability organisations, such as the Halberg Allsports Sundays sports programme and Parafed Canterbury-Junior Sports Club, were only available on a weekly basis.

In regions where adapted sports were available, parents reported that many adapted sports were mostly tailored to children with severe impairments (for example, wheelchair basketball and wheelchair rugby), and therefore younger children or older children with what may be perceived as more "minor" impairments (for example, amputations) missed out. As a parent of a child expressed:

He sort of doesn't really fit in either world... So it's like really disabled kids or completely able bodied. Like we've spent a lot of time going into the disabled world to see if we can find kids like [child's name] and it's very rare. (Parent \#20)
In particular, for children with minimal movement impairment, participation in team sports was challenging, as they neither fitted into wheelchair groups nor fitted into teams of ablebodied peers. A parent elucidated:

I really like the idea of having him [child] as part of a team, but I can also see that that can be quite hard... I remember the day when he was saying, mum, mum, I almost got the ball today. And that can be a bit of a hard, you know if you always feel that you can't quite keep up. In terms of that actually you know it would be fantastic if I could find a football team with other kids that had similar issues, you know that would be the ideal. (Parent \#15)

While most parents felt that it would be more ideal if their children could play team sports with children of similar movement abilities, they also described the difficulties associated with trying to compose teams of children with similar movement abilities because, for example, there were too few children in their area who used a wheelchair.

It was parents of children living in rural areas or small towns who most significantly felt that there were few organised recreational opportunities available for their child, although this concern was also reported by parents in the bigger centres. A parent living in a rural area explained the drawback of limited adapted sports in a rural setting:

Rural living has plusses e.g. good local school, friends. But would often like to live nearer to city for sports, library, swimming etc and to do things with other kids with similar 
ability. For example, netball etc. can be challenging when [he] can't use one arm very well. (Parent \#3)

Even if adapted community programmes were available, a lack of information about these community programmes and a lack of suitable transport were frequently reported as barriers. Parents also recommended the need for "publicising" the existing adapted community programmes. Lack of information regarding leisure activities was identified as a barrier by $51 \%$ of families from the survey data. Parents explained that they had to search a number of websites of disability organisations to explore the opportunities available in their community.

Thus, children were restricted in their choice of adapted activities, even though they could perform and enjoy such activities. The difficulty in keeping up with peers and/or the competitive nature of many able-bodied sports teams resulted in children in our study preferring individual rather than team sports or free play activity, such as going to a park.

\section{School environment}

The survey data identified lack of assistance at school (71\%) and inadequate education policies for inclusion of all children in school activities (58\%) as barriers. This result was supported by findings from the interviews. Both parents and children reported that school physical education (PE) at all ages was not inclusive for children with impairments. Furthermore, they reported that although children were mostly included in school sports when they were younger, this became far less as they got older and team sports became more competitive. For example, a parent of a teenage child expressed that her child "hasn't played sports for school since primary school". Similarly, a child who used a prosthetic lower limb explained:

... basically, at school I don't like PE. I mean I just don't like enjoy it because like they don't like do the kind of sports that I do, like... they do like running-based sports and you know that's obviously like not the best thing for me so yeah. (Child \#2, 12 years)

Parents were of the opinion that PE teachers were not supported enough to be able to adapt sports based on children's abilities. They acknowledged it was a "constant struggle" for $P E$ teachers to organise team sports for only a few children with impairments. In some cases, parents reported the PE teachers might not have time to supervise their children individually whilst participating in an activity that was different to what the rest of the class was doing. As one parent explained,

She normally uses a wheelchair for long distances. But in school [child's name] plays just [a] short time with her friends by walking. But playing this is the most difficult activity for her. We told the teachers and explained that [child's name] needs to be involved in physical activities but the teacher does not have enough time to supervise child's name] [different] activities. I think. (Parent \#17)

Neighbourhood In the survey data, $80 \%$ of the families identified the natural environment, including terrain and temperature, as a major barrier. In addition, homes of friends in the neighbourhood that were not easily accessible were perceived as a challenge for children to develop and/or establish friendships. Parents explained how they had to carefully choose leisure environments that were accessible for their children. A parent described how her daughter used to visit and be included in a leisure activity with a friend through the friend's parent's adaptation of their home environment. She also explained that this had come to an end because the family had moved neighbourhoods so that the two friends were no longer able to get together.

She used to go down (to her friend's place in the neighbourhood) every day and the mum had set up the couch and stereo and stuff in the garage. They used to go down there in the garage because she can't just go to someone's house, because she can't get inside... So of course most kids' houses aren't wheelchair friendly... So it's a more complicated when they can't just go somewhere. (Parent \#4)

In addition, neighbourhood environments, such as community pools, parks and natural terrains, were reported to be not easily accessible, and families often identified this as restricting the options of leisure environments available for their children. For example, a parent explained that they did not take their child to a community pool due to an inaccessible changing table:

We are just waiting for [name of the facility] to get a better change table for the pool. Because her change table is only as this big [gesticulating] so you put her on it and her head touches the end and her legs will hang off the other end so it's not the best. (Parent \#4)

Although parents were aware of a number of leisure environments, such as bush walks or bike tracks, they reported that many were not suitable for independent wheelchair users.

So yeah, I'll show you his hand cycle, it's out in the garage, that's it... so the running bit is the struggle, mostly because a lot of the courses are like this, they're across grass so this is the one thing we're still figuring out with him. (Parent \#9)

In regions where adapted community sports were not available, children often relied on free play in the neighbourhood parks and playgrounds. A child explained:

I... sometimes I play with the next-door neighbour. Yeah, 'cause both of us, he's about a year younger... just hang around and... it's pretty safe back here so we just go back and forth between the houses, there's nowhere else really to go... (Child \#9)

A child who used a wheelchair explained that although his motorised wheelchair was a way to get around with friends when outside, it was not suitable for playing games or sports as it lacked agility. Frequent breakdowns and heaviness of the wheelchair were also considered barriers. Some parents of children who used a motorised wheelchair emphasised the importance of indoor play areas as free play outdoors was not possible in rainy/cold weather, especially when children wore orthotics or orthotic shoes that would have to be removed when wet. 


\section{DISCUSSION}

This mixed method study explored environmental factors influencing leisure participation of children with movement impairments in Aotearoa/New Zealand, using survey and indepth individual interviews. The overarching finding from the study suggests a disparity between a child's ability and existing leisure activity opportunities in various settings, particularly with increasing age. Examples were given of limited tailoring of community-based programmes, non-inclusive school-based PE programmes and inaccessible neighbourhood environments.

Lack of adapted inclusive community sports/events and the lack of information regarding available activities were identified as a major concern for families who lived in sparsely populated areas, had older children or had children with minor impairments. A previous study undertaken in Aotearoa/ New Zealand, which examined 32 children with cerebral palsy using the adult version CHIEF questionnaire, identified $56 \%$ of children had barriers related to community services. In particular, the inability to participate in sports and afterschool activities were reported as major obstacles that could be related to lack of funding for additional equipment and poor structural design of pavements, playgrounds and stairs (Vogts, Mackey, Ameratunga, \& Stott, 2010). Indeed, studies in other parts of the world have also identified a lack of adapted and/or inclusive community programmes, a lack of information about programmes, the competitiveness of programmes and a lack of skilled instructors as barriers (Bedell et al., 2013; Columna, Pyfer, \& Senne, 2011; Jones, 2003). While a lack of adapted sports was a major concern, difficulty forming teams of children with similar movement abilities in a geographically distinct area because of the small population size in Aotearoa/New Zealand was highlighted by participants in our study as the reason why children often pursued non-team leisure activities. In particular, in our study, it was the older children who experienced more exclusion than younger children, possibly because their ablebodied peers became more competitive as they got older while their own movement limitations restricted their ability to manage the increasing complexity of leisure activities. A study of parents of children with developmental coordination disorder found similar barriers with the increasing age of their children (Missiuna, Moll, King, King, \& Law, 2007). This particular study identified that although younger children may have problems with play activities, such as riding a bicycle, as they aged, they experienced increased difficulty keeping up with their peers, which had the potential to lead to emotional problems, such as low self-esteem, in later childhood.

To improve participation of children with movement impairments and their families in community-based leisure activities, a combined effort from therapists and community service providers could be helpful. Therapists could take a more proactive role in providing information and suggesting suitable inclusive activities available within the community, depending on individual need of the child and the family preferences. Such action has been a recommendation from studies undertaken in other countries (Majnemer, 2009; Palisano et al., 2012; Shimmell et al., 2013). In Aotearoa/New Zealand, adaptive and inclusive sports events are mainly provided by disability organisations at regional and national levels. These organisations depend on volunteers to conduct adapted programmes, and therapists could team with these organisations to help and support leisure activities of children with movement impairments. In addition, therapists could liaise with community service providers to further develop adapted sports to facilitate the choice of team sports for children with similar movement abilities. Such teams would be ideal for children's participation and enjoyment. However, in communities where there are insufficient numbers of children to form a team (a common scenario in sparsely populated countries such as Aotearoa/ New Zealand), an adaptive non-competitive sport, which could include both adults and children, is a possible solution. Indeed, a variety of adapted sports that cater to children with different abilities and promotes their confidence and enjoyment can act as a facilitator to physical activity (Verschuren, Wiart, Hermans, \& Ketelaar, 2012). Given the lack of adapted team sports in some regions, it would seem useful for therapists to proactively explore and promote the availability of adaptive individualised activities that could be performed in groups, such as swimming karate, and dancing

Although there are various national networks for children with impairments in Aotearoa/New Zealand. such as the Halberg Foundation, the Cerebral Palsy Society of New Zealand and the Muscular Dystrophy Association of New Zealand, the opportunities for leisure activities provided by them are limited in terms of frequency and their availability in different regions. Finding and collating information through a number of disability organisation's websites about leisure opportunities that would suit the interest and ability of their child was considered a difficult process by the parents in our study. Thus, physiotherapists could actively collaborate with regional disability organisations in their work area to collect and keep updated information on available leisure opportunities, and suggest activities that might be suitable for children they work with. Instead of individual websites, a national website that collates information from various organisations and lists all the activities available in different regions would make it easier to share information, thereby supporting families to support their child to become involved in activities. When the opportunity to participate in an appropriate adaptive sport in the community is available, transporting children to such events may need to be provided. This is especially necessary to support parents who do not have an appropriate vehicle to accommodate their child's adaptive equipment, such as a motorised wheelchair, and parents who have to support other children to attend different sporting activities. However, these services require additional funding.

The lack of assistance at school and the attitudes of other children coupled with the competitive nature of team sports in schools resulted in inadequate inclusion of children with movement impairments in PE at school. Specifically, children with mild and moderate impairments who did not receive funding for a teacher aide or therapist support faced difficulty playing team sports as they could not keep up with their peers. 
Similar findings were supported by a city-based Aotearoa/ New Zealand study conducted by Vogts et al. (2010) who identified $72 \%$ of children had barriers related to attitudes of others at school and $56 \%$ had barriers related to inadequate support at school. In particular, others' attitudes, such as lack of understanding about a child's limitations and inadequate teacher aide hours, were reported as major obstacles at school. Non-inclusive PE at school could restrict teamwork and lunchtime play activities, during which friendships could be built and then strengthened. Lack of adaptation to physical activities performed at school could lead children to not being accepted by peers, and this could affect the self-esteem of a child (Missiuna et al., 2007). Further, friendships at school naturally open up opportunities for social and play activities after school, for example sleepovers, friends visiting and birthday parties. Thus, it would seem important to have inclusive PE classes in the school setting as well as other opportunities for children to make and sustain friendships.

In Aotearoa/New Zealand, children with severe impairments are supported at school through the Ongoing Resourcing Scheme or the Physical Disability Service, which provide teacher aide hours and therapist support from physiotherapists and occupational therapists. Depending on the funding, therapists visit these children on a consultative basis or termly visit (term on, term off basis) and provide ideas for parents, teachers and teacher aides to facilitate activities. Therapists could proactively update themselves with various modified sports developed for children with impairments, and play an active role in planning a suitable adapted, inclusive activity for an individual child, and liaise with PE teachers and teacher aides to support physical activity. However, providing access to support staff with training in inclusive PE for children with all levels of impairments might require funding from the Ministry of Education. Further research on how the health and physical education curriculum is put into practice, and the challenges involved, could improve the physical activity of children with impairments at school. Carter et al. (2014) suggested that if adapted, inclusive sports, such as wheelchair sports, were available to all children, this could then help able-bodied children to understand the challenges faced by children with movement impairments, and to learn that even though people are different, they can be respected for this and can be valued for their contributions.

Inaccessible leisure environments were perceived as a barrier, and families avoided taking their children to such environments. This finding concurs with a recent evaluation study of 21 neighbourhood parks and playgrounds in a city region in New Zealand, which found none of the parks evaluated met national/ international standards for playground design (Perry et al., 2018). Interestingly, only a third of the parks had accessible routes to ground level play components and only four had an accessible route to elevated play equipment, thus limiting the usability of the parks for children with impairments (Perry et al., 2018). If park environments were designed to meet the needs of users of all ages and abilities, then this may provide positive health benefits by maximising park-based physical activity, particularly for children with impairments (Saitta, Devan, Boland, \& Perry, 2019). Indeed, an inaccessible environment has been reported as the most frequently encountered barrier to participation by children with movement impairments in the international literature (Colver et al., 2012; Law, Petrenchik, King, \& Hurley, 2007; Shields, Synnot, \& Barr, 2012).

Therapists could provide information on accessible and inclusive leisure environments suitable for the child's impairment and their family in their neighbourhood. Furthermore, therapists in collaboration with Accessibility Advisory Groups of city councils could advocate for modifications to playgrounds and park equipment to improve their accessibility and usability. Providing interventions in the form of task training for improving skills required for mastery within the natural environment, such as negotiating uneven terrain in a wheelchair, could be helpful (Palisano et al., 2012). For children with severe impairments, exploring options for technology-based adaptive interactive games, such as video games that incorporate physical activity for children, could be a possible option to promote leisure activity for these children. Furthermore, development and provision of equipment, such as light-weight and agile motorised wheelchairs, would result in easier handling by children during sporting and leisure activities, and therefore be more favorable to facilitating inclusion of such children.

Lastly, to maximise the opportunities for leisure activities of children, a proactive and collaborative approach will be required from many individuals (including physiotherapists) and from organisations, such as councils, sports bodies, schools and non-governmental organisations. There is a need to provide services and advocate for children, so that those who live with impairments and who currently experience inequity of access to leisure activities, can be fully included in society and take part in activities that they enjoy.

\section{CONCLUSION}

Currently, there is a disparity between the needs of children with impairments and the leisure opportunities provided at school, in the community and in neighbourhoods in Aotearoa/ New Zealand. Participation in leisure activities for these children could be improved with increased opportunities for adapted sports and community programmes. On one hand, health professionals, such as physiotherapists and occupational therapists, may need to be more proactive in discovering and developing strategies to minimise the barriers to participation in leisure activities for the children and their families to whom they provide services. On the other hand, community sport and recreational providers could help by addressing the availability, opportunities and options for leisure activities suitable for children with variable levels of movement impairment. To maximise the benefits of leisure-based physical activity, concerted efforts are required among health professionals, including physiotherapists, PE teachers, disability organisations and local policymakers, in creating adaptive/inclusive leisure activity programmes for children of all ages and abilities at school, and in the local neighbourhood and wider community. 


\section{KEY POINTS}

1. There is a mismatch between the needs of children with impairments and their leisure activity requirements and the opportunities provided in the community, at school and in neighbourhood environments in Aotearoa/New Zealand.

2. Therapists could play an important role by tailoring activities for children, based on their abilities and preferences as well as recommending child-friendly, accessible leisure environments in the community.

3. Concerted efforts are required between health professionals, including physiotherapists, PE teachers, disability organisations and local policymakers, in creating adaptive/ inclusive leisure activity programmes for children of all ages and abilities at school, and in the local neighbourhood and wider community.

\section{DISCLOSURES}

This study was supported by the Wilson Home Trust Research Grant; Physiotherapy New Zealand Paediatric Special Interest Group Study Award; University of Otago Physiotherapy Research Fund Grant-in-Aid; School of Physiotherapy PhD fund; and Otago University PhD scholarship. There are no conflicts of interest which may be perceived to interfere with or bias this study.

\section{PERMISSIONS}

This study was approved by the University of Otago Human Ethics (Health) Committee (ref: 12/314 and 13/132).

\section{ACKNOWLEDGEMENTS}

We wish to thank all the children and their parents who participated in our study. For helping us recruit children for our study, we thank the members of disability organisations, therapists working for the Ministry of Education, and Child Development Services of the Auckland and Canterbury District Health Boards, and regional Movement Development Clinic.

\section{ADDRESS FOR CORRESPONDENCE}

Dr Parimala S. Kanagasabai, Centre for Health, Activity and Rehabilitation Research, School of Physiotherapy, University of Otago, PO Box 56, Dunedin 9054, New Zealand. Telephone: +64 22355 7801. Email: pari.suganthini@gmail.com.

\section{REFERENCES}

Almqvist, L., Uys, C. J., \& Sandberg, A. (2007). The concepts of participation, engagement and flow: A matter of creating optimal play experiences. South African Journal of Occupational Therapy, 37(3), 8-13.

Anaby, D., Hand, C., Bradley, L., Direzze, B., Forhan, M., Digiacomo, A., \& Law, M. (2013). The effect of the environment on participation of children and youth with disabilities: A scoping review. Disability and Rehabilitation, 35(19), 1589-1598. https://doi.org/10.3109/09638288.2012.748840

Bedell, G., Coster, W., Law, M., Liljenquist, K., Kao, Y.C., Teplicky, R., ... Khetani, M. A. (2013). Community participation, supports, and barriers of school-age children with and without disabilities. Archives of Physical Medicine and Rehabilitation, 94(2), 315-323. https://doi.org/10.1016/j. apmr.2012.09.024

Carter, B., Grey, J., McWilliams, E., Clair, Z., Blake, K., \& Byatt, R. (2014). 'Just kids playing sport (in a chair)': experiences of children, families and stakeholders attending a wheelchair sports club. Disability and Society, 29(6), 938-952. https://doi.org/10.1080/09687599.2014.880329
Creswell, J.W., \& Plano Clark, V.L. (2011). Designing and conducting mixed methods research (2nd ed.). Los Angeles: Sage Publications.

Columna, L., Pyfer, J., \& Senne, T.A. (2011). Physical recreation among immigrant Hispanic families with children with disabilities. Therapeutic Recreation Journal, 45(3), 214-233.

Colver, A., Thyen, U., Arnaud, C., Beckung, E., Fauconnier, J., Marcelli, M., ... Dickinson, H. O. (2012). Association between participation in life situations of children with cerebral palsy and their physical, social, and attitudinal environment: A cross-sectional multicenter European study. Archives of Physical Medicine and Rehabilitation, 93(12), 2154-2164. https://doi. org/10.1016/j.apmr.2012.07.011

Hammal, D., Jarvis, S.N., \& Colver, A.F. (2004). Participation of children with cerebral palsy is influenced by where they live. Developmental Medicine and Child Neurology, 46(5), 292-298. https://doi. org/10.1111/j.1469-8749.2004.tb00488.x

Jones, D.B. (2003). "Denied from a lot of places" Barriers to participation in community recreation programs encountered by children with disabilities in Maine: Perspectives of parents. Leisure/Loisir, 28(1-2), 49-69. https://doi. org/10.1080/14927713.2003.9649939

Kanagasabai, P. S., Mulligan, H., Mirfin-Veitch, B., \& Hale, L. A. (2017). Leisure participation patterns of children with movement impairments in New Zealand. Pediatric Physical Therapy, 29(1), 16-22. https://doi. org/10.1097/PEP.0000000000000334

Kanagasabai, P. S., Mirfin-Veitch, B., Hale, L. A., \& Mulligan, H. (2018). A child-centered method of interviewing children with movement impairments. Physical \& Occupational Therapy In Pediatrics, 38(3), 255268. https://doi.org/10.1080/01942638.2017.1365322

King, G., Imms, C., Palisano, R., Majnemer, A., Chiarello, L., Orlin, M., ... Avery, L. (2013). Geographical patterns in the recreation and leisure participation of children and youth with cerebral palsy: A CAPE international collaborative network study. Developmental Neurorehabilitation, 16(3), 196-206. https://doi.org/10.3109/17518423.2 013.773102

Kramer, J., Olsen, S., Mermelstein, M., Balcells, A., \& Liljenquist, K. (2012). Youth with disabilities' perspectives of the environment and participation: A qualitative meta-synthesis. Child: Care, Health and Development, 38(6), 763-777. https://doi.org/10.1111/j.1365-2214.2012.01365.x

Law, M., Petrenchik, T., King, G., \& Hurley, P. (2007). Perceived environmental barriers to recreational, community, and school participation for children and youth with physical disabilities. Archives of Physical Medicine and Rehabilitation, 88(12), 1636-1642. https://doi.org/10.1016/j. apmr.2007.07.035

Majnemer, A. (2009). Promoting participation in leisure activities: Expanding role for pediatric therapists. Physical and Occupational Therapy in Pediatrics, 29(1), 1-5. https://doi.org/10.1080/01942630802625163

McCauley, D., Gorter, J. W., Russell, D. J., Rosenbaum, P., Law, M., \& Kertoy, M. (2012). Assessment of environmental factors in disabled children 2-12 years: Development and reliability of the Craig Hospital Inventory of Environmental Factors (CHIEF) for Children-Parent Version. Child: Care, Health and Development, 39(3), 337-344. https://doi.org/10.1111/j.13652214.2012.01388.x

Michelsen, S.I., Flachs, E.M., Uldall, P., Eriksen, E.L., McManus, V., Parkes, J., ... Colver, A. (2009). Frequency of participation of 8-12-year-old children with cerebral palsy: A multi-centre cross-sectional European study. European Journal of Paediatric Neurology, 13(2), 165-177. https://doi. org/10.1016/j.ejpn.2008.03.005

Missiuna, C., Moll, S., King, S., King, G., \& Law, M. (2007). A trajectory of troubles: Parents' impressions of the impact of developmental coordination disorder. Physical and Occupational Therapy in Pediatrics, 27(1), 81-101. https://doi.org/10.1080/J006v27n01_06

Palisano, R.J., Chiarello, L. A., King, G. A., Novak, I., Stoner, T., \& Fiss, A (2012). Participation-based therapy for children with physical disabilities. Disability and Rehabilitation, 34(12), 1041-1052. https://doi.org/10.3109/0 9638288.2011 .628740 
Perry, MA., Devan, H., Fitzgerald, H., Han, K., Liu, L., \& Rouse, J. (2018) Accessibility and usability of parks and playgrounds. Disability and Health Journal, 11(2), 221-229. https://doi.org/10.1016/j.dhjo.2017.08.011

Saitta, M., Devan, H., Boland, P., \& Perry, MA. (2019). Park-based physical activity interventions for persons with disabilities: A mixed-methods systematic review. Disability and Health Journal, 12(1):11-23. https://doi. org/10.1016/j.dhjo.2018.07.006

Shields, N., Synnot, A.J., \& Barr, M. (2012). Perceived barriers and facilitators to physical activity for children with disability: A systematic review. British Journal of Sports Medicine, 46(14), 989-997. https://doi.org/10.1136/ bjsports-2011-090236

Shikako-Thomas, K., Majnemer, A., Law, M., \& Lach, L. (2008). Determinants of participation in leisure activities in children and youth with cerebral palsy: Systematic review. Physical and Occupational Therapy in Pediatrics, 28(2), 155-169. https://doi.org/10.1080/01942630802031834

Shimmell, L.J., Gorter, J.W., Jackson, D., Wright, M., \& Galuppi, B. (2013). "It's the participation that motivates him": Physical activity experiences of youth with cerebral palsy and their parents. Physical and Occupational Therapy in Pediatrics, 33(4), 405-420. https://doi.org/10.3109/01942638. 2013.791916

Thomas, D.R. (2006). A general inductive approach for analyzing qualitative evaluation data. American Journal of Evaluation, 27(2), 237-46. https:// doi.org/10.1177/1098214005283748
Ullenhag, A., Bult, M. K., Nyquist, A., Ketelaar, M., Jahnsen, R., KrumlindeSundholm, L., ... Granlund, M. (2012). An international comparison of patterns of participation in leisure activities for children with and without disabilities in Sweden, Norway and the Netherlands. Developmental Neurorehabilitation, 15(5), 369-385. https://doi.org/10.3109/17518423.2 012.694915

Verschuren, O., Wiart, L., Hermans, D., \& Ketelaar, M. (2012). Identification of facilitators and barriers to physical activity in children and adolescents with cerebral palsy. Journal of Pediatrics, 161(3), 488-494. https://doi. org/10.1016/j.jpeds.2012.02.042

Vogts, N., Mackey, A.H., Ameratunga, S., \& Stott, N.S. (2010). Parentperceived barriers to participation in children and adolescents with cerebral palsy. Journal of Paediatrics and Child Health, 46(11), 680-685. https://doi. org/10.1111/j.1440-1754.2010.01815.x

Welsh, B., Jarvis, S., Hammal, D., \& Colver, A; North of England Collaborative Cerebral Palsy Survey. (2006). How might districts identify local barriers to participation for children with cerebral palsy? Public Health, 120(2), $167-$ 175. https://doi.org/10.1016/j.puhe.2005.04.006

World Health Organisation (WHO) (2007). International classification of functioning, disability, and health - version for children and youth (ICFCY). Geneva, WHO 